Jurnal Ilmiah Magister Agribisnis, 1(2) 2019: 146-151,
D0I:
A

\title{
Analisis Pengaruh Perubahan Kebiasaan Makan Terhadap Kontinuitas Produksi Telur Itik Di Kabupaten Batu Bara
}

\section{Analysis of the Effects of Changing Eating Habits Towards Continuity of Duck Egg Production In the Regency of Coal}

\section{Misnun'1), Hasnudi'2), Muhammad Akbar Siregar ${ }^{3)}$}

1) Program Studi Magister Agribisnis, Pascasarjana, Universitas Medan Area, Indonesia 2) Departemen Peternakan, Fakultas Pertanian, Universitas Sumatera utara, Indonesia 3) Magister Agribisnis, Pascasarjana, Universitas Medan Area, Indonesia

\begin{abstract}
Abstrak
Tujuan dari penelitian ini adalah untuk mengungkap apakah perubahan kebiasaan makan pada itik petelur memberikan pengaruh negatif terhadap kontinuitas produksi telur. Penelitian dilakukan di Kabupaten Batu Bara dengan melakukan survei kepada 35 (tiga puluh lima) peternak yang ada di sembilan desa di tiga kecamatan. Peternak yang dijadikan objek penelitian adalah peternak dengan pola pemeliharaan secara intensif dan secara tradisional. Jenis penelitian yang dilakukan adalah penelitian kuantitatif deskriptif dan data yang digunakan adalah data primer. Metode yang digunakan dalam pengumpulan data menggunakan metode survei melalui penyebaran kuesioner. Analisis data yang digunakan pada penelitian ini adalah analisis regresi linear sederhana. Hasil dari penelitian ini yaitu perubahan kebiasaan makan berpengaruh negatif terhadap kontinuitas produksi telur itik. Hal ini menerangkan bahwa ada hubungan yang berlawanan antara perubahan kebiasaan makan itik terhadap kontinuitas produksi telur.
\end{abstract}

Kata kunci: itik, peternak, telur, regresi

\begin{abstract}
The purpose of this study was to reveal whether changes in eating habits in laying ducks had a negative influence on the continuity of egg production. Keywords: superior fruits, production value, worthiness. The study was conducted in Batu Bara District by conducting a survey of 35 (thirty-five) breeders in nine villages in three sub-districts. The breeders that are used as the object of research are breeders with intensive and traditional maintenance patterns. This type of research is descriptive quantitative research and the data used are primary data. The method used in data collection uses survey methods through questionnaires. Analysis of the data used in this study is a simple linear regression analysis. The results of this study are changes in eating habits negatively affect the continuity of duck egg production. This explains that there is an opposite relationship between changes in duck eating habits to the continuity of egg production.
\end{abstract}

Keywords: breeders, ducks, eggs, regression

How to Cite: Misnun, Hasnudi, \& M. A. Siregar. (2019). Analisis Pengaruh Perubahan Kebiasaan Makan terhadap Kontinuitas Produksi Telur Itik di Kabupaten Batu Bara. Jurnal Ilmiah Magister Agribisnis, 1(2) 2019: 146-151, 


\section{PENDAHULUAN}

Kegiatan beternak itik petelur telah sejak lama dikenal oleh masyarakat pedesaan, tidak terkecuali bagi masyarakat perdesaan yang tinggal di Kabupaten Batu Bara Provinsi Sumatera Utara. Beternak itik secara tradisional dengan cara membebaskan itik mencari makan di persawahan adalah cara yang paling banyak dilakukan. Ada juga beberapa peternak yang menjalankan usaha ternak itik dengan menempatkan itik-itik di dalam kandang. Apapun cara yang dilakukan dalam beternak itik, tujuan utamanya dalah untuk mendapatkan telurnya.

Bagi peternak yang membiasakan ternaknya mencari makan di persawahan, selalu terkendala apabila memasuki musim tanam padi. Itik-itik yang semula dilepas terpaksa harus dikurung untuk mencegah agar tidak mengganggu padi-padi yang telah ditanam. Para peternak harus menyediakan pakan untuk itik-itik selama itik tersebut dikandangkan. Namun tidak hanya masalah penyediaan pakan, para peternak juga akan mendapatkan kerugian akibat itik-itik yang telah dikandangkan akan berhenti bertelur.

Lain lagi untuk peternak yang biasa memelihara itik di dalam kandang, mereka terpaksa harus melepas itik-itiknya apabila sudah tidak sanggup lagi memenuhi kebutuhan pakan itik yang dipelihara. Mereka juga harus menerima konsekuensi dari tindakan yang telah mereka lakukan, yaitu tidak akan pernah lagi menerima telur dari itik-itik yang mereka pelihara. Kondisi demikian pasti akan mereka dapatkan apabila cara-cara seperti it uterus dilakukan.

Faktor lingkungan atau pemeliharaan yang ikut mempengaruhi produktivitas itik diantaranya adalah kesehatan itik, mutu dan kestabilan pakan, kondisi kandang, suhu, iklim dan stres. Dengan sifat itik sebagai hewan yang anti perubahan, maka apbila salah satu faktor tersebut terganggu maka produktivitas telur akan terganggu atau bahkan terhenti sama sekali. Dengan kata lain faktor lingkungan sangat berperan dalam panjang atau lamanya produktivitas itik petelur. Bila itik sakit, pakan berubah, kandang becek dan berbau, hujan lebat atau banjir atupun stres tertentu akan mengurangi jumlah telur yang dihasilkan dari yang semestinya (Yuwono, 2012). Produktivitas itik yang dipelihara merupakan indikator keberhasilan usaha peternakan itik petelur. Atau dengan kata lain produktivitas itik petelur merupakan cerminan dari kualitas usaha peternakan, dengan mengenyampingkan faktor kualitas telur maka semakin tinggi dan lamanya produktivitas itik yang dipelihara maka semakin baik usaha peternakan tersebut (Nugraha, dkk., 2013).

Berdasarkan kondisi tersebut, dapat diduga bahwa perubahan kebiasaan makan pada itik yang dipelihara secara intensif ataupun secara tradisional, dipandang cukup berpengaruh terhadap kontinuitas produksi telur itik. Untuk mengetahui apakah perubahan kebiasaan makan pada itik berpengaruh negatif terhadap kontinuitas produksi telur, maka perlu dilakukan proses penelitian. Penelitian ini akan dilakukan dengan cara melakukan survei melalui penyebaran kuisioner kepada para peternak itik. Lokasi penelitian berada pada 9 (sembilan) desa di 3 (tiga) kecamatan wilayah Kabupaten Batu Bara (Kecamatan Lima Puluh (Desa Lubuk Cuik, Gambus Laut, Perupuk), Kecamatan Air Putih (Desa Aras, Tanah Rendah, Tanah Tinggi), dan Kecamatan Medang Deras (Desa Kuala Tanjung, Kuala Indah, Nanasiam)) Sumatera Utara, dengan 
mengangkat judul penelitian "Analisis Pengaruh Perubahan Kebiasaan Makan Terhadap Kontinuitas Produksi Telur Itik Di Kabupaten Batu Bara (Kecamatan Lima Puluh, Kecamatan Air Putih, Kecamatan Medang Deras)". Tujuan dari penelitian ini adalah untuk mengungkap apakah perubahan kebiasaan makan pada itik petelur memberikan pengaruh negatif terhadap kontinuitas produksi telur.

\section{METODE PENELITIAN}

Waktu penelitian dilaksanakan selama 2 (dua) bulan, mulai dari Bulan Agustus sampai dengan September 2017. Penelitian dilakukan di Kabupaten Batu Bara dengan melakukan survei kepada 35 (tiga puluh lima) peternak yang ada di sembilan desa di tiga kecamatan. Peternak yang dijadikan objek penelitian adalah peternak dengan pola pemeliharaan secara intensif dan secara tradisional.

Desa-desa yang dipilih adalah Desa Perupuk, Gambus Laut dan Lubuk Cuik (Kecamatan Lima Puluh), Desa Aras, Tanah Rendah dan Tanah Tinggi (Kecamtan Air Putih), Desa Kuala Tanjung, Kuala Indah dan Nenas Siam (Kecamatan Medang Deras). Pemilihan lokasi dilakukan secara sengaja (purposive), berdasarkan keterjangkauan pengumpulan data. Jenis penelitian yang dilakukan adalah penelitian kuantitatif deskriptif dan data yang digunakan adalah data primer. Data primer merupakan sumber data yang diperoleh secara langsung dari sumber asli. Metode yang digunakan dalam pengumpulan data menggunakan metode survei melalui penyebaran kuesioner.

Analisis data yang digunakan pada penelitian ini adalah analisis regresi linear sederhana. Analisis regresi merupakan salah satu alat analisis yang menjelaskan tentang akibat-akibat dan akibat yang ditimbulkan oleh satu atau lebih variabel bebas terhadap satu variabel terikat (tidak bebas). Regresi Linear Sederhana adalah regresi yang memiliki satu variabel independen (X) dan satu variabel dependen (Y). Analisis Regresi Sederhana ini bertujuan untuk menguji pengaruh antara variabel $\mathrm{X}$ terhadap variabel $\mathrm{Y}$. Model persamaan regresi linier sederhana sebagai berikut:

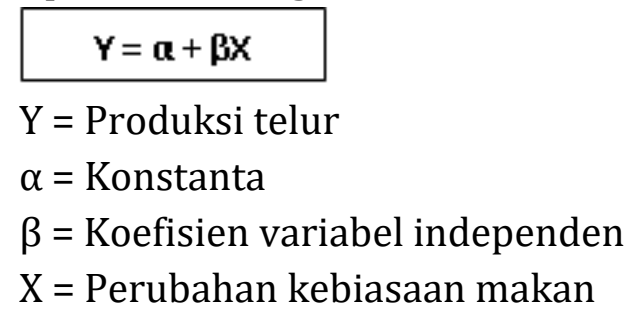

Untuk menjawab hipotesis statistik yang menggunakan alat uji analisis regresi linier, dapat dilakukan dengan 2 cara, yaitu : 1) Membandingkan nilai Signifikansi dengan nilai Probabilitas 0,05; 2) Membandingkan nilai t hitung dengan t tabel.

\section{HASIL DAN PEMBAHASAN}

Metode analisis yang digunakan yaitu analisis regresi linear sederhana. Untuk mempermudah dalam menganalisis data, semua pengolahan data diakukan dengan menggunakan program SPSS (Statistical Package for Sosial Science) dan Ms. Office Excel. 
Tabel 1. Model Summary

\begin{tabular}{ccrrr}
\hline Model & $\mathrm{R}$ & $\mathrm{R}$ Square & Adjusted R Square & Std. Error of the Estimate \\
\hline 1 &, $965^{\text {a }}$ &, 932 &, 912 & 150,196 \\
\hline a. Predictor: (Constant), Perubahan kebiasaan makan & & &
\end{tabular}

b. Dependen Variabel : Kontinuitas produksi telur, Y

Sumber :Data Primer (diolah), 2017

Tabel 1 menjelaskan tentang besarnya nilai korelasi atau hubungan yang dilambangkan dengan (R), yaitu sebesar 0,965. Sedangkan pada kolom R Square menjelaskan besarnya persentase (\%) pengaruh variabel Independent $(\mathrm{X})$ terhadap variabel Dependent $(\mathrm{Y}$ ) yang disebut dengan koefisien determinasi. Dari Tabel diperoleh nilai koefisien determinasi (R2) sebesar 0,932 artinya bahwa pengaruh variabel (perubahan kebiasaan makan) terhadap variabel (kontinuitas produksi telur) adalah sebesar 93,2\%, sedangkan sisanya dipengaruhi oleh variabel lain di luar penelitian.

Tabel 2. Tabel ANOVA

\begin{tabular}{|c|c|c|c|c|c|c|}
\hline & Model & $\begin{array}{c}\text { Sum of } \\
\text { Squares }\end{array}$ & $\mathrm{df}$ & $\begin{array}{c}\text { Mean } \\
\text { Square }\end{array}$ & $\mathrm{F}$ & Sig. \\
\hline \multirow[t]{3}{*}{1} & Regression & 5231,064 & 1 & 5231,064 & 32,555 &, $000^{a}$ \\
\hline & Residual & 9319,669 & 58 & 160,684 & & \\
\hline & Total & 14550,733 & 59 & & & \\
\hline
\end{tabular}

a. Predictors : (Constant), Perubahan kebiasaan makan

b. Dependen Variable : Kontinuitas produksi telur

Sumber :Data Primer (diolah), 2017

Tabel ANOVA fungsinya adalah untuk menjelaskan apakah ada pengaruh yang signifikan antara variabel Perubahan kebiasaan makan $(\mathrm{X})$ terhadap variabel Kontinuitas produksi telur (Y). Dari output tersebut nilai $\mathrm{F}$ hitung $=32,555$ dengan tingkat signifikansi < probabilitas $(0,000<0,05)$ maka model regresi dapat digunakan untuk memprediksi variabel Kontinuitas produksi telur (Y).

Tabel 3. Hasil Uji Regresi Linear Sederhana

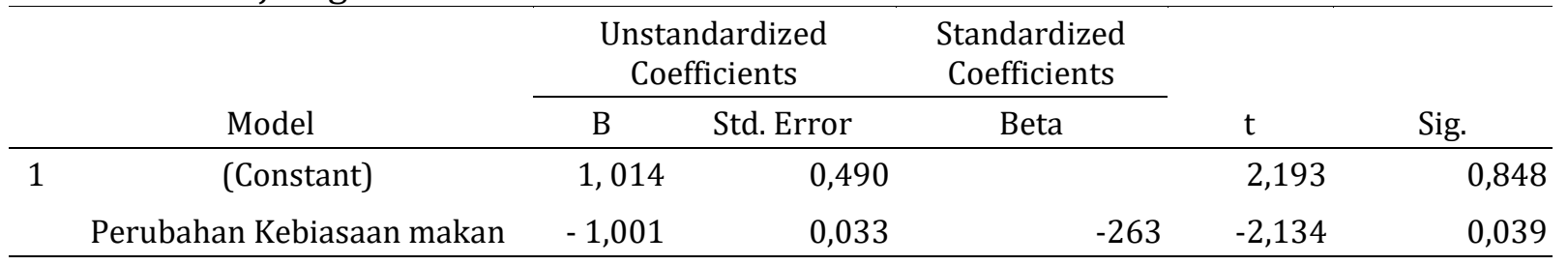

a. Dependent Variable: Kontimuitas Produksi Telur

Sumber :Data Primer (diolah), 2017

Berdasarkan rumus regresi, koefisien (b) dinamakan koefisien arah regresi linier yang fungsinya menyatakan perubahan rata-rata variabel $(Y)$ untuk setiap perubahan variabel $(X)$ sebesar satu satuan. Perubahan tersebut merupakan pertambahan apabila nilai (b) bertanda positif ( + ) dan pengurangan jika nilai (b) bertanda negatif (-). Makna positif $(+)$ atau negatif $(-)$ tersebut diinterpretasikan dalam besaran satuan. Jika positif maka naik sebesar satu satuan, jika negatif maka turun sebesar satu satuan (Eko Hertanto, 2016). Berdasarkan tabel 3 dapat diperoleh model persamaan regresi sebagai berikut : 
Misnun, Hasnudi, \& M. A. Siregar. Analisis Pengaruh Perubahan Kebiasaan Makan terhadap Kontinuitas Produksi Telur Itik di Kabupaten Batu Bara.

$$
\begin{aligned}
& \mathrm{Y}=\alpha+\beta \mathrm{X} \\
& \mathrm{Y}=1,014-1,001 \mathrm{X}
\end{aligned}
$$

Konstanta $\alpha$ sebesar 1,014 artinya apabila perubahan kebiasaan makan itik tidak dilakukan atau nilainya adalah 0 , maka kontinuitas produksi telur itik nilainya 1,014. Sedangkan untuk koefisien regresi perubahan kebiasaan makan (X) sebesar -1,001, artinya apabila dilakukan perubahan kebiasaan makan itik, maka kontinuitas produksi telur akan mengalami penurunan sebesar 1,001 satuan. Koefisien bernilai negatif, artinya ada hubungan yang berlawanan antara perubahan kebiasaan makan itik terhadap kontinuitas produksi telur.

Untuk mengetahui apakah variabel independen (X) secara parsial berpengaruh nyata atau tidak terhadap variabel dependen (Y) perlu dilakukan uji perbandingan nilai signifikan dengan nilai probabilitas. Derajat signifikansi yang digunakan adalah 0,05. Apabila nilai signifikan lebih kecil dari derajat kepercayaan maka kita menerima hipotesis alternatif, yang menyatakan bahwa suatu variabel independen (X) secara parsial mempengaruhi variabel dependen (Y). Perubahan kebiasaan makan itik (X) terhadap kontinuitas produksi telur (Y) berdasarkan hasil perhitungan sebelumnya diperoleh nilai signifikan 0,039. Nilai signifikan lebih kecil dari nilai probabilitas 0,05, atau nilai $0,039<0,05$, maka $\mathrm{H} 1$ diterima dan Ho ditolak.

Jika nilai thitung < t tabel , maka Ho diterima (artinya: tidak ada pengaruh yang signifikan). Jika nilai thitung $>\mathrm{t}$ tabel, maka Ho ditolak (artinya: ada pengaruh yang signifikan). Variabel X mempunyai thitung yakni 2,134 dengan ttabel $=2,021$. Jadi thitung > ttabel dapat disimpulkan bahwa variabel $\mathrm{X}$ memiliki kontribusi terhadap $\mathrm{Y}$. Nilai t negatif menunjukkan bahwa $\mathrm{X}$ mempunyai hubungan yang berlawanan arah dengan Y. Jadi dapat disimpulkan perubahan kebiasaan makan memiliki pengaruh signifikan terhadap kontinuitas produksi telur.

Dari hasil penelitian menunjukkan bahwa perubahan kebiasaan makan pada itik petelur memberikan pengaruh negatif yang signifikan terhadap kontinuitas produksi telur. Nilai signifikan yang lebih kecil dari nilai probabilitas 0,05 , atau nilai $0,039<0,05$, secara nyata menunjukkan bahwa perubahan kebiasaan makan (X) berpengaruh signifikan terhadap kontinuitas produksi telur (Y).

Dari hasil uji t juga menunjukkan bahwa perubahan kebiasaan makan pada itik (X) berpengaruh negatif secara signifikan terhadap kontinuitas produksi telur (Y). Hal ini dapat dilihat dari variabel $\mathrm{X}$ yang mempunyai nilai thitung yakni 2,134 dengan ttabel = 2,021. Jadi thitung > ttabel dapat disimpulkan bahwa variabel $X$ memiliki pengaruh signifikan terhadap Y. Nilai t negatif menunjukkan bahwa X mempunyai hubungan yang berlawanan arah dengan $Y$. Jadi dapat disimpulkan perubahan kebiasaan makan memiliki pengaruh signifikan terhadap kontinuitas produksi telur.

\section{SIMPULAN}

Kesimpulan dari penelitian ini yaitu perubahan kebiasaan makan berpengaruh negatif terhadap kontinuitas produksi telur itik. Hal ini menerangkan bahwa ada hubungan yang berlawanan antara perubahan kebiasaan makan itik terhadap kontinuitas produksi telur. Peternak itik petelur secara intensif diharapkan dapat 
mempersiapakan kebutuhan pakan dalam jumlah yang cukup selama satu siklus masa bertelur itik, karena itik sangat sensitif terhadap peruhan pakan yang dapat berdampak pada terhentinya produksi telur. Para peternak itik petelur secara tradisional diharapkan dapat mempertimbangkan lokasi pelepasan itik untuk mencari makan berdasarkan perhitungan masa panen dan masa tanam padi, agar tidak mengganggu kebiasaan itik dalam mencari makan di sawah.

Perubahan kebiasaan makan itik yang dilakukan secara drastis positif berpengaruh negatif terhadap kontinuitas produksi telur itik, untuk itu diharapkan dapat dilakukan penelitian terhadap variabel lain yang yang berhubungan dengan kontinuitas produksi telur itik. Variabel perubahan kebiasaan makan, kuesioner yang digunakan oleh peneliti masih terbatas dan pertanyaannya masih kurang memadai, oleh sebab itu pada penelitian selanjutnya dapat menambah dan memperbaiki pertanyaan-pertanyaan yang ada dalam penelitian ini. Jumlah responden dalam penelitian ini masih sediki, hanya 35 responden, dan penyebarannya juga masih pada 3 kecamatan, oleh sebab itu pada penelitian selanjutnya dapat menambah sampel yang akan digunakan, sehingga akan hasil penelitian yang diperoleh dapat lebih akurat. Diharapkan pada penelitian selanjutnya untuk melakukan pengujian pada satu jenis itik tertentu.

\section{DAFTAR PUSTAKA}

BPS Sumatera Utara, Provinsi Sumatera Utara Dalam Angka 2016. Medan.

Dinas Peternakan Kabupaten Batu Bara, Rencana Strategis Dinas Peternakan Kabupaten Batu Bara Tahun 2013-2018.

Elang Ilik, M., Eko Martanto., dan Netti Tinaprilla. 2004. Panduan Beternak Itik Petelur Secara Intensif. PT. Agromedia Pustaka. Jakarta.

Handayani, M., A. Setiadi., S. Gayatri dan H. Setiyawan. 2007. Profil Usaha Peternakan Itik Di Kabupaten Brebes (The Profile of Duck Business in Brebes Regency). Journal of Animal Agricultural Socioeconomics. Laboratorium Sosial Ekonomi Peternakan. Fakultas Peternakan.Universitas Diponegoro.

Nitisemito, A.S dan Burhan, M.U. 2004. Wawasan Study Kelayakan dan Evaluasi $\quad$ Proyek. Bumi Aksara. Jakarta.

Retno dan Maloedyn Sitanggang. 2007. Panduan Lengkap Beternak Itik. Agromedia Pustaka. Jakarta

Sipora, Srianna., Ira Wadani Harahap., dan Zulka Hidayati. 2009. Usaha Itik Petelur Dan Telur Tetas. Program Studi Manajemen Hutan. Departemen Kehutanan. Fakultas Pertanian. Universitas Sumatera Utara. Medan.

Siswoyo Haryono, dan Wardoyo, Parwoto, 2013, "Structural Equation Modeling Untuk Penelitian Manajemen Menggunakan AMOS 18.00”, PT. Intermedia Personalia Utama, Bekasi, Jawa Barat.

Nugraha, Fajar Sandi., Muhammad Mufti., dan Ibnu Hari S. 2013. Kualitas Telur $\quad$ Itik yang Dipelihara Secara Terkurung Basah dan Kering di Kabupaten Cirebon. Jurnal Ilmiah Peternakan. Fakultas peternakan. Universitas Jendral Soedirman. Purwokerto.

Yuwono, Dian Maharso. 2012. Budidaya Ternak Itik Petelur. Badan Penelitian dan Pengembangan Pertanian. Balai Besar Pengkajian dan Pengembangan Teknologi Pertanian. Balai Pengkajian Teknologi Pertanian. Jawa Tengah. 